\title{
The crucial role of SEMA3F in suppressing the progression of oral squamous cell carcinoma
}

\author{
Yi Liu* (D), Ronghua Li, Kai Yin, Gang Ren and Yongdong Zhang
}

\author{
* Correspondence: \\ 13821075639@163.com \\ Department of Stomatology, Tianjin \\ First Center Hospital, Tianjin 300192, \\ People's Republic of China
}

\begin{abstract}
Background: Oral squamous cell carcinoma (OSCC) is one of the most common types of malignancy. Semaphorin 3F (SEMA3F) is highly conserved but present at a lower level in various cancers than in healthy tissues. While it has been reported that SEMA3F is involved in cancer cell proliferation, migration and invasion, its function in OSCC remains unknown.

Methods: The expression of SEMA3F in OSCC tissues and OSCC-derived cells was analyzed using qRT-PCR and western blotting. Using SAS and HSC2 cells, we also monitored the effect of SEMA3F on OSCC cell proliferation, migration and invasion using MTT, colony formation and transwell assays. The function of SEMA3F in OSCC tumor formation was also assessed in vivo.

Results: SEMA3F was significantly downregulated in OSCC tissues and OSCC-derived cells. SEMA3F shows growth inhibitory activity in SAS and HSC2 cells and may act as a tumor suppressor. It can inhibit the migration and invasion potential of OSCC cells. Our results also demonstrate that SEMA3F can suppress the growth of OSCC cells in vivo.

Conclusions: This study revealed that SEMA3F plays a role as a tumor suppressor in OSCC cell proliferation, migration and invasion. Our finding provides new insight into the progression of OSCC. Therapeutically, SEMA3F has some potential as a target for OSCC treatment, given sufficient future research.

Keywords: Oral cancer, SEMA3F, Cell proliferation, Migration, Invasion, MTT assay, Transwell assay, Xenograft model
\end{abstract}

\section{Background}

Oral squamous cell carcinoma (OSCC) is the most common malignant neoplasm of the oral cavity $[1,2]$. According to the recent investigation of its pathogenesis and management, OSCC affects approximately 300,000 individuals per year worldwide, and the five-year survival rate for patients remains as low as $60 \%$ [3-5]. The presence of metastatic spread to the regional lymph nodes strongly correlates with a poor overall prognosis [6-8].

Despite considerable advances in the treatment of OSCC over the past two decades, the understanding of its pathogenesis is limited $[9,10]$. Recent investigations of molecular alterations in various oncogenes and antitumor genes associated with OSCC development may help to address this $[3,11,12]$.

(c) The Author(s). 2017 Open Access This article is distributed under the terms of the Creative Commons Attribution 4.0 International License (http://creativecommons.org/licenses/by/4.0/), which permits unrestricted use, distribution, and reproduction in any medium, provided you give appropriate credit to the original author(s) and the source, provide a link to the Creative Commons license, and indicate if changes were made. The Creative Commons Public Domain Dedication waiver (http://creativecommons.org/ publicdomain/zero/1.0/) applies to the data made available in this article, unless otherwise stated. 
Semaphorin 3F (SEMA3F), was first identified as a repulsive factor with a role in axonal guidance and neuronal development, where it modulates cell polarization and migration [13]. It has been reported that the SEMA3F gene is on chromosome 3p21.3 and that it is commonly deleted during cancer development [14-17]. SEMA3F is one of the microenvironmental factors with a tumor suppressor function [18-20].

The expression of SEMA3F in cancer cells inhibits tumor growth, invasion and metastasis [21-25]. It has been reported that SEMA3F was an inhibitor of OSCC progression [26]. However, there is very little evidence for a correlation between SEMA3F levels and OSCC progression.

In this study, we tested SEMA3F expression in 16 OSCC tissues and 4 OSCC-derived cell lines via qRT-PCR, and found that SEMA3F was downregulated in OSCC tissues and OSCCderived cell lines. We then validated that SEMA3F suppressed OSCC cell growth, invasion and migration. Our data further demonstrated that SEMA3F inhibited OSCC tumor formation in vivo. These findings provide new insight into the mechanism of OSCC pathogenesis.

\section{Materials and methods}

Patient characteristics

Tissues were obtained from 30 OSCC patients at the Tianjin First Center Hospital. Written informed consent was obtained from all patients and the study was approved by the ethics committees of the Tianjin First Center Hospital.

\section{Immunohistochemistry}

The OSCC tissues were embedded with paraffin and sectioned. The sections were subjected to a routine three-step immunohistochemical (IHC) staining procedure. The slides were incubated with rabbit anti-SEMA3F antibody (1:200 dilution; Sigma) and anti-Ki67 antibody (1:200 dilution; Proteintech Group) at $4{ }^{\circ} \mathrm{C}$ overnight. Then, the slides were incubated with horseradish peroxidase-labelled secondary antibody for $30 \mathrm{~min}$ at room temperature. The chromogen 3,3'-diaminobenzidine tetrachloride (DAB; Zhongshanjinqiao) was used as a substrate.

The cell nucleus was dyed with Harris hematoxylin solution. Levels of SEMA3F expression were determined based on the extent and intensity of staining with the scoring using this scale: negative for $<5 \%$, weak for $5-25 \%$, mid for $25-50 \%$, distinct for $50-75 \%$, and strong for $\geq 75 \%$. The staining intensity and stained area percentage were multiplied to produce a weighted score. Three independent evaluators assessed the scoring.

\section{Cell culture}

We used 4 human OSCC-derived cell lines: SAS, Ca9-22, HSC2 and HSC4. One normal oral keratinocyte strain was obtained from a patient who had undergone dental surgery. This served as the control. The patient provided written informed consent prior to the start of the study. The cell lines were cultured in DMEM (Thermo-Fisher) with $10 \%$ fetal bovine serum (FBS) plus $100 \mathrm{IU} / \mathrm{ml}$ penicillin and $100 \mu \mathrm{g} / \mathrm{ml}$ streptomycin at $37^{\circ} \mathrm{C}$ in a humidified atmosphere with $5 \% \mathrm{CO}_{2}$.

\section{Plasmid construction}

The CDS sequence of SEMA3F was obtained via PCR using specific primers. The PCR products were cloned into the pcDNA3.1(+) vector. The plasmid was named pcDNA-SEMA3F. 
The primers were: SEMA3F forward: 5'-CTAGCTAGCATGCTTGTCGCCGGTC-3'; SEMA3F reverse: 5'-CTAGTCTAGATCATGTGTCCGGAG-3' .

\section{Cell transfection}

Transfection of cells was performed using Lipofectamine 2000 (Invitrogen) according to the manufacturer's protocol. Briefly, cells were seeded in 6-well plates at 30-40\% confluence $24 \mathrm{~h}$ prior to transfection. pcDNA-SEMA3F ( $2 \mu \mathrm{g}$ per well) and the control were used for each transfection.

For stable transfection, HSC2 cells were selected in G418 (800 mg/ml). Individual G418resistant colonies were isolated after 15 days of culture. Cells were treated with G418 $(200 \mathrm{mg} / \mathrm{ml})$ and maintained in culture until needed for subcutaneous inoculation into mice.

\section{MTT and colony formation assays}

The MTT assay was performed daily over 3 days to evaluate cell proliferation. First, cells were transfected with plasmids (control or pcDNA-SEMA3F). After $24 \mathrm{~h}$, cells were seeded into 96 -well plates $\left(3 \times 10^{3}\right.$ cells/well). Next, the cells were incubated with $25 \mu \mathrm{l}$ of MTT ( $5 \mathrm{mg} / \mathrm{ml}$, Sigma) at $37{ }^{\circ} \mathrm{C}$ for $4 \mathrm{~h}$, the supernatants were removed, and $150 \mu \mathrm{l}$ methylsulfoxide (DMSO; Sigma) was added to each well. The absorbance value (OD) of each well was measured at $490 \mathrm{~nm}$.

For the colony formation assay, cells $\left(5 \times 10^{5}\right.$ cells per well) were seeded in 6 -well plates and transfected with pcDNA-SEMA3F $(2 \mu \mathrm{g}$ per well) or the control for $24 \mathrm{~h}$. The medium was refreshed every 3 days. After 2-3 weeks of culture, the colonies were fixed with methanol, stained with $1.25 \%$ crystal violet and counted under a light microscope. All experiments were performed three times and the average results were calculated.

\section{Quantitative RT-PCR}

Total RNA was extracted using Trizol reagent (Takara). Then, $1 \mu \mathrm{g}$ of the RNA was converted to cDNA using Revert Acid Reverse Transcriptase (Fermentas). Real-time PCR was conducted using a Sigma-Aldrich FastStart Universal SYBR Green Master (ROX) Kit according to the manufacturer's instructions. Double-stranded DNA specific expression was tested by the comparative $\mathrm{Ct}$ method using 2- $\Delta \Delta \mathrm{Ct}$. The sequence of the primers used were: SEMA3F forward: 5'-CTCTGGGCTTCCCTACTGAC-3'; reverse: 5'-CACTCGCCGTTGACATCC-3'; GAPDH forward: 5'-ATCACCATCTTCCAGGAGCG A-3'; reverse: 5'-CCTTCTCCAT GGTGGTGAAGAC-3'. Experiments were performed in triplicate.

\section{Western blot}

Cellular proteins were extracted in RIPA buffer (Biomed) after transfection for $48 \mathrm{~h}$. Proteins were separated by gel electrophoresis and transferred to membranes, which were then incubated with primary antibodies. The concentrations and sources of the antibodies were: rabbit polyclonal anti-NRP2 (1:2000; Abclonal), rabbit polyclonal antiSEMA3F (1:2500; Sigma) and mouse monoclonal antihuman anti-GAPDH (1:2000; Abcam). Treatment with secondary antibodies diluted in PBST was done at room temperature for $1 \mathrm{~h}$. Membranes were washed in PBST and the bound antibody was detected using an enhanced chemiluminescence system. The experiments were repeated three times. 


\section{Migration assay}

Cells were transfected with pcDNA-SEMA3F and the control. After $48 \mathrm{~h}$, the cells were seeded on the upper chamber of an $8-\mu \mathrm{m}$ pore size transwell insert (Costar) at $2.5 \times$ $10^{4}$ cells/insert in DMEM. The lower chamber contained DMEM (600 $\mu$ l) with 10\% FBS. The migrated cells were fixed with $4 \%$ paraformaldehyde in PBS and stained in $0.5 \%$ crystal violet. The membranes were mounted on a microscope slide. Migrated cells were counted and photographed. The percentage of migrated cells was calculated. The migration index was expressed relative to the control cells. All the experiments were carried out three times and the results were expressed as the means \pm SD.

\section{Cell invasion assay}

Cell invasion assays were performed in 24-well plates using transwell chambers $(8.0 \mu \mathrm{m}$ pore size, Millipore) were coated with matrigel. The cells were transfected and then seeded in the upper chamber at a density of $2 \times 10^{5}$ cells $/ \mathrm{ml}$ in $400 \mu \mathrm{l}$ of medium containing $0.5 \%$ FBS. Medium with $10 \%$ FBS was added to the lower chamber. Following $24 \mathrm{~h}$ incubation at $37{ }^{\circ} \mathrm{C}$ with $5 \% \mathrm{CO}_{2}$, the invading cells were fixed in $100 \%$ methanol and stained with $0.5 \%$ crystal violet. Photographs were taken randomly for at least four fields of each membrane. The number of invading cells was expressed as the average number of cells per microscopic field over four fields.

\section{In vivo tumor xenograft model}

A total of twelve nude mice (4-week old BALB/c nude mice; Huafukang) were randomly divided into two groups. HSC2 cells stably transfected with pcDNA-SEMA3F and control were inoculated subcutaneously into the flanks of nude mice. The length and width of tumors were taken with Vernier calipers every five days, and the mice were euthanized after thirty days. The volume of the implanted tumor was calculated using the formula: volume $=\left(\right.$ length $\times$ width $\left.^{2}\right) / 2$. All animals were treated according to the guidelines established by the National Institutes of Health Guide (NIH).

\section{Statistical analysis}

Results were analyzed statistically using Student's $t$-test for comparisons between two groups. Data are presented as the means \pm SD. Analyses were performed using SPSS 20.0. $p<0.05$ and $p<0.01$ were considered to be statistically significant. Unless indicated, the results shown in the figures are representative. All the experiments were done at least three times.

\section{Results}

Expression of SEMA3F in oral cancer tissue samples and cells

To identify the role of SEMA3F in oral carcinogenesis, we tested the expression levels of SEMA3F in a cohort of OSCC tissues and adjacent normal tissues using qRT-PCR. Our data showed that the SEMA3F mRNA levels were significantly lower in OSCC tissues than in noncancerous tissues (Fig. 1a). We also analyzed the protein level of SEMA3F in OSCC tissues and their adjacent noncancerous tissues via IHC. SEMA3F expression was generally lower in OSCC tissues than in adjacent normal tissues (Fig. 1b). 


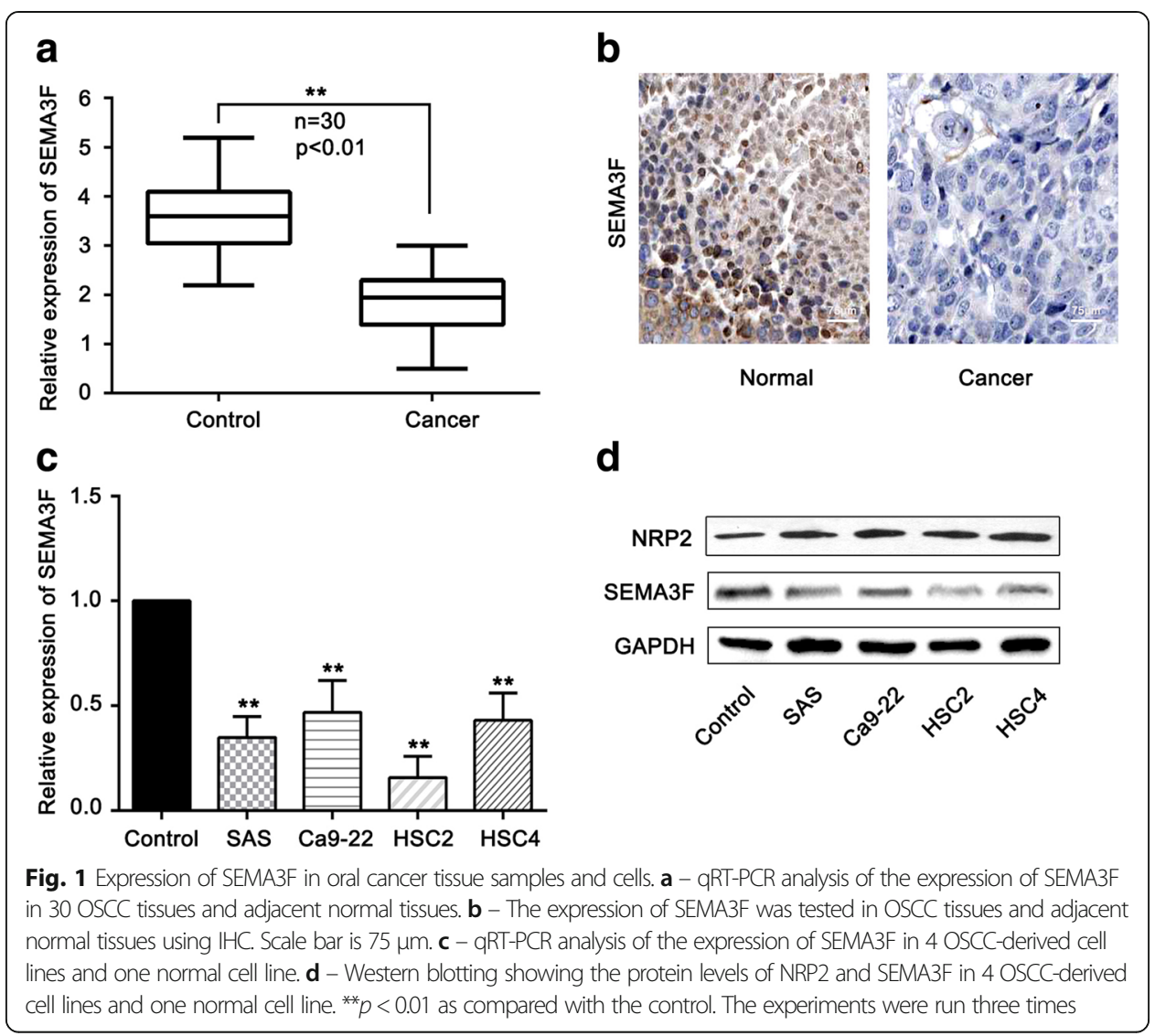

In addition, we tested the expression of SEMA3F in 4 human OSCC-derived cell lines (SAS, Ca9-22, HSC2, and HSC4) and one normal oral keratinocyte strains (control) using qRT-PCR (Fig. 1c). The expression of SEMA3F in the 4 OSCCderived cell lines was tested using western blot technology (Fig. 1d). We also tested the expression level of NRP2, a receptor of SEMA3F, in the above-mentioned OSCC cells. We found that NRP2 was significantly upregulated in OSCC cells compared with control cells (Fig. 1d).

These results show that SEMA3F was significantly downregulated in OSCC cells compared with control cells at both the mRNA and protein levels. This suggests that SEMA3F may be a tumor suppressor in OSCC.

\section{SEMA3F inhibits cell proliferation in oral cancer cells}

To detect the effect of SEMA3F on OSCC cell growth, we cloned the SEMA3F CDS and transfected it into the human OSCC cell lines SAS and HSC2. Increased expression of SEMA3F upon transfection was confirmed using qRT-PCR and western blot (Fig. 2a and b). As demonstrated in MTT assays, SEMA3F restoration dramatically inhibited OSCC cell proliferation (Fig. 2c and d). The inhibitory effect of SEMA3F on OSCC cell growth was further confirmed with colony formation assays. The number of colonies for cells transfected with pcDNA-SEMA3F was significantly lower than for cells transfected with the control (Fig. 2e and $\mathrm{f}$ ). This means that SEMA3F inhibits the growth ability in SAS and HSC2 cells and acts as a potential OSCC tumor suppressor. 


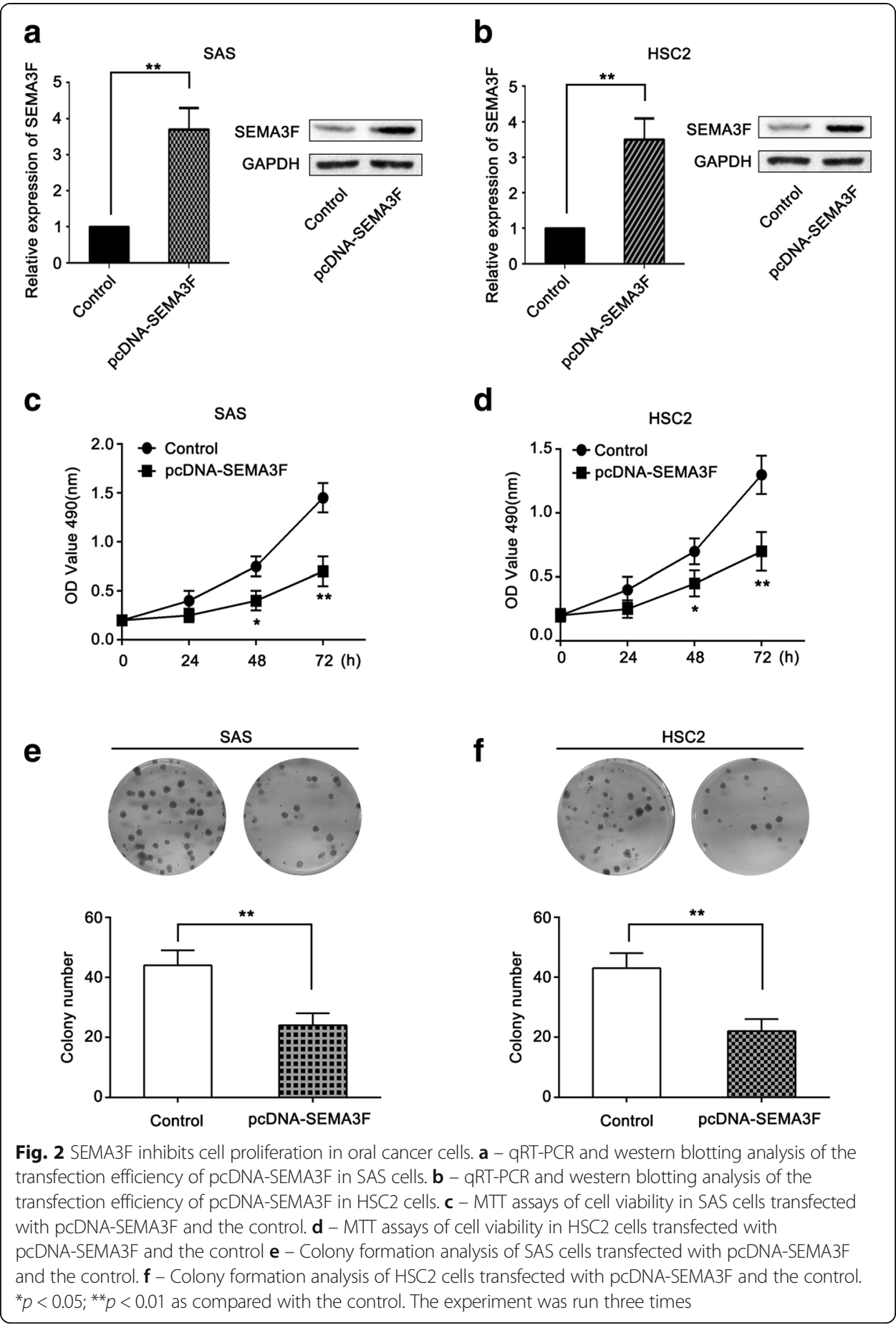

SEMA3F suppresses oral cancer cell migration and invasion

We attempted to identify the effect of SEMA3F on OSCC cell migration and invasion according to the potent capacity of OSCC to invade locally and form distant metastases. We used the transwell migration assay for this experiment. Our results showed that the rate of migration for SAS and HSC2 cells transfected with pcDNA-SEMA3F was significantly lower than for control transfected cells (Fig. 3a and b). Furthermore, the transwell invasion assays showed that the number of cells that passed through Matrigel-coated membrane into the lower 


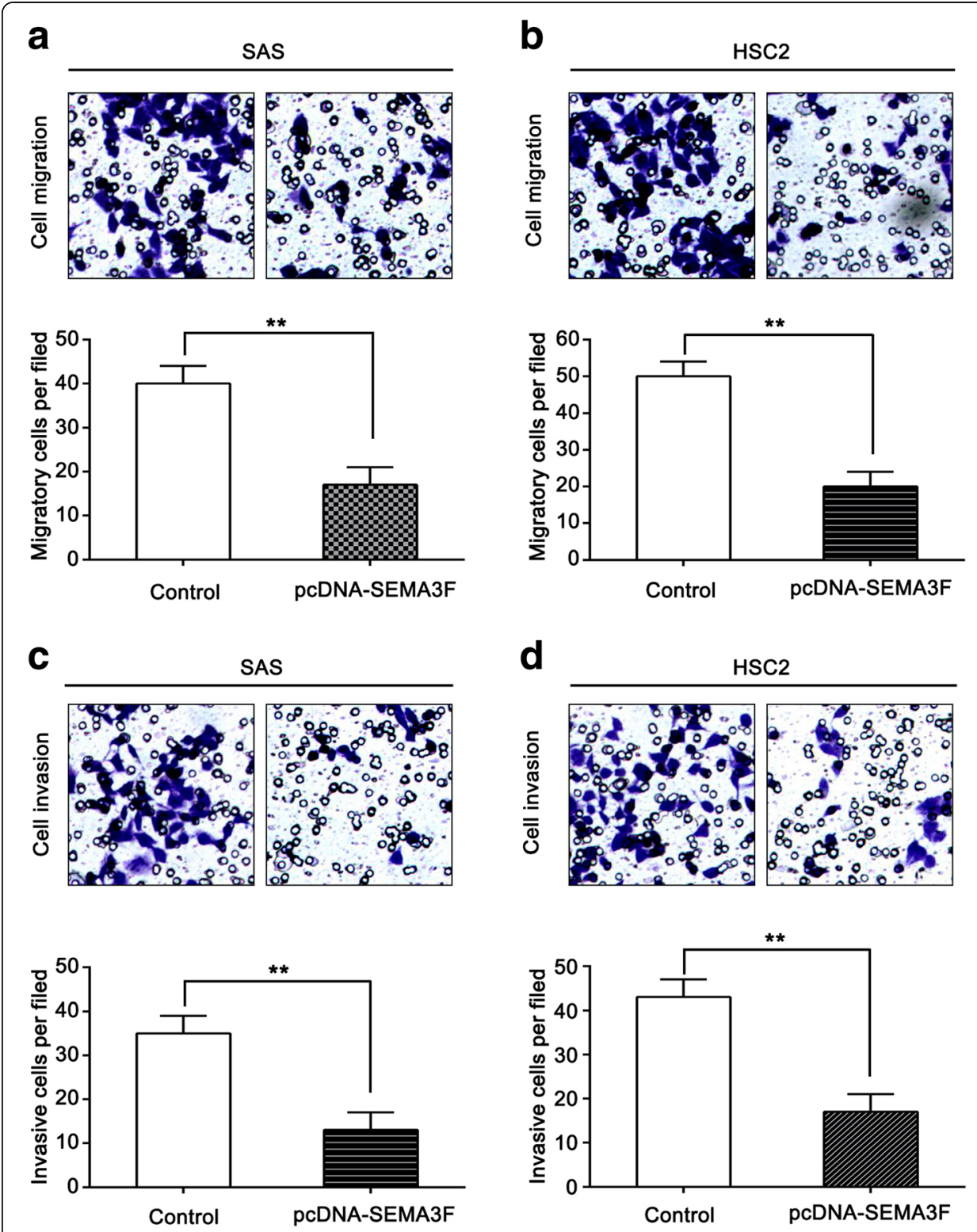

Fig. 3 SEMA3F suppresses oral cancer cell migration and invasion. a - Transwell assays of cell migration in SAS cells. $\mathbf{b}$ - Transwell assays of cell migration in HSC2 cells. $\mathbf{c}$ - Transwell assays of cell invasion in SAS cells. $\mathbf{d}$ - Transwell assays of cell invasion in HSC2 cells. ${ }^{* *} p<0.01$ as compared with the control. The experiment was run three times

chamber was significantly lower for cells transfected with pcDNA-SEMA3F than for the control transfected cells (Fig. 3c and d). These results suggest that SEMA3F can inhibit the migration and invasion potential of OSCC cells.

Effect of SEMA3F expression on the progression of oral cancer in vivo

To explore whether changes in SEMA3F expression could influence the growth of OSCC tumors in vivo, two groups of nude mice were subcutaneously injected with HSC2 cells stably transfected with pcDNA-SEMA3F and control plasmids. Tumor formation and weight were assessed in these two groups. Our results showed that the ectopic expression of SEMA3F 
inhibited OSCC tumorigenesis in vivo (Fig. 4a). The average tumor weight of mice inoculated with pcDNA-SEMA3F-transfected HSC2 cells was significantly lower than that of mice inoculated with the control cells (Fig. 4b).

We also tested the expression levels of SEMA3F in the tumors from mice using the IHC assay. Our data revealed that SEMA3F levels were higher in pcDNA-SEMA3F-transfected HSC2 cells group than in the control group (Fig. 4c). In addition, we tested the expression levels of Ki-67, a biomarker of cell growth, in the tumor tissues. Our results show that the Ki-67 expression level was significantly lower in the pcDNA-SEMA3F-transfected HSC2 cells group than in the control group (Fig. 4d). Thus, we conclude that SEMA3F is able to suppress the growth of OSCC cells in vivo.

\section{Discussion}

Recent study of SEMA3F has shown that it can play crucial roles in the regulation of cell proliferation, migration and invasion [21, 22, 27, 28]. SEMA3F is causally

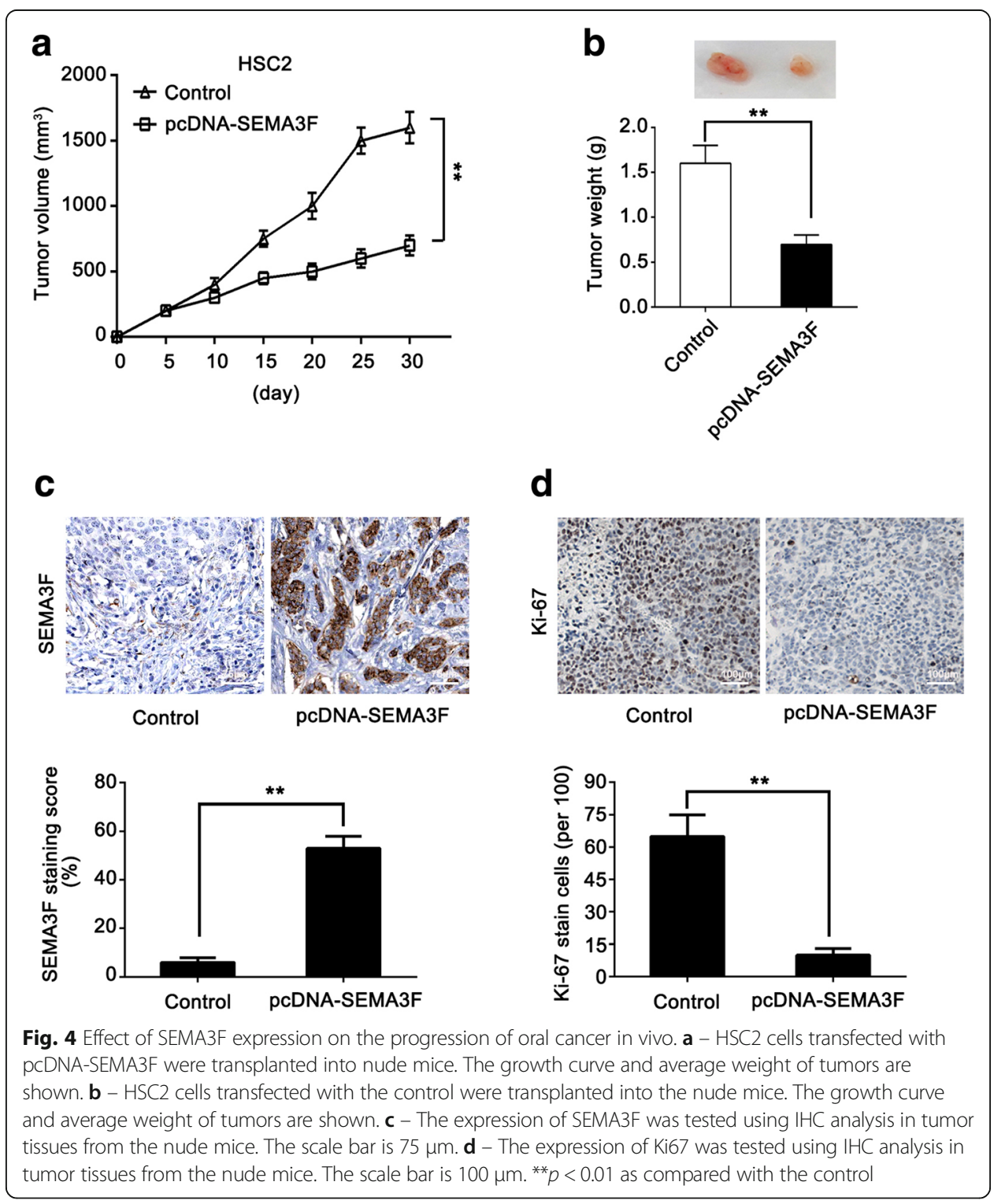


downregulated in the initiation and progression of some cancers [20, 22, 23, 27]. However, the role of SEMA3F in oral carcinogenesis remains unkown. In this study, we attempted to investigate the expression of SEMA3F in OSCC tissues and adjacent normal tissues, and explored its biological function in oral carcinogenesis.

Firstly, we tested the expression of SEMA3F in 30 pair of OSCC tissues and adjacent normal tissues. Our data show that SEMA3F is significantly downregulated in OSCC tissues compared with adjacent normal tissues. The relative expression of SEMA3F in 4 human OSCC-derived cell lines (SAS, Ca9-22, HSC2 and HSC4) was also significantly downregulated compared with normal control cells.

Zhang et al. demonstrated that the expression level of SEMA3F is downregulated in OSCC cancer tissues [26]. Our results are consistent with that and other earlier reports. This suggests that SEMA3F is a candidate tumor suppressor in the pathogenesis of OSCC.

It has been reported that NRP2 is a receptor of SEMA3F, so we tested the expression levels of NRP2 and SEMA3F in OSCC cells. We found that the NRP2 protein level was upregulated but that the SEMA3F protein level was downregulated. This suggests that there would be a SEMA3F/NRP2 axis pathway during the progression of OSCC.

Functional studies were required to clarify the role of SEMA3F in the development of OSCC cells. We tested the function of SEMA3F, as a putative tumor suppressor, in SAS and HSC2 cell lines. Overexpression of SEMA3F in SAS and HSC2 cells shows a significant growth-suppressing effect through the inhibition of cell proliferation and colony formation.

It has been reported that SEMA3F suppressed the migration and invasion of several cancers [29-32]. To better understand the tumor suppressive effect of SEMA3F in oral tumorigenesis, we identified the function of SEMA3F in SAS and HSC2 cell lines using transwell analysis. Notably, we found that SEMA3F inhibits OSCC cell migration and invasion. These data suggest that SEMA3F inhibits growth, migration and invasion in SAS and $\mathrm{HSC} 2$ cells and acts as a potential tumor suppressor in OSCC pathogenesis.

In addition, we observed that overexpression of SEMA3F could significantly decrease the OSCC tumor volume and weight in vivo. Our data confirmed that $\mathrm{Ki}-67$, a marker of proliferation, was induced in the restoration of the SEMA3F group. Thus, we conclude that SEMA3F is able to suppress the proliferation of OSCC in vivo.

In summary, our data show that SEMA3F is significantly downregulated in OSCC tissues and OSCC-derived cells. Our study is the first to demonstrate that SEMA3F inhibits OSCC cell growth, migration and invasion in vitro and in vivo. This means that SEMA3F may be a potential biomarker for OSCC diagnosis and could serve as a new target for OSCC therapy in the future.

\section{Conclusion}

We show that the SEMA3F plays an important role in OSCC cell proliferation, migration and invasion. Our finding is definitely important for studies on the development of OSCC, since it may provide new insight into the role of SEMA3F in OSCC cancer progression and be helpful in the development of further targeted drugs for OSCC cancer treatment. 


\section{Abbreviations}

FBS: Fetal bovine serum; GAPDH: Glyceraldehyde-3-phosphate dehydrogenase; MTT: 3-(4,5-dimethyl-2-thiazolyl)-2,5diphenyl-2-H-tetrazolium bromide; OD: Absorbance value; OSCC: Oral squamous cell carcinoma; qRT-PCR: quantitative reverse transcription PCR; SEMA3F: Semaphorin 3F

\section{Acknowledgments}

We are grateful to the personnel of the pathology department of Tianjin First Center Hospital for their assistance with the IHC instrument and analyses.

\section{Funding}

This work was supported in part by grant $06 \mathrm{KZ7}$ from the Tianjin Health Bureau Research Fund.

\section{Availability of data and materials}

The datasets supporting the conclusion of this article are included within the article.

\section{Authors' contributions}

$Y L$ conceived the idea, designed the study and contributed to the data analysis and writing of the manuscript. RL helped to conduct the experiments and data analysis and contributed to the writing of the manuscript. KY performed the cell migration and invasion assay. GR performed the qRT-PCR and western blotting assays. YZ performed the experiments involving tumor formation in mice. All authors read and approved the final manuscript.

\section{Ethics approval and consent to participate}

Not applicable.

\section{Consent for publication}

Not applicable.

\section{Competing interests}

The authors declare that they have no competing interests.

\section{Publisher's Note}

Springer Nature remains neutral with regard to jurisdictional claims in published maps and institutional affiliations.

\section{Received: 8 August 2017 Accepted: 15 December 2017}

Published online: 28 December 2017

\section{References}

1. Stewart B and Wild C. World cancer report 2014. International Agency for Research on Cancer, 2014.

2. Scully C, Bagan J. Oral squamous cell carcinoma overview. Oral Oncol. 2009;45:301-8.

3. Sannam KR, Khurshid Z, Akhbar S, Faraz MS. Advances of salivary proteomics in oral squamous cell carcinoma (OSCC) detection: an update. Proteomes. 2016;4:41. https://doi.org/10.3390/proteomes4040041.

4. Genden EM, Ferlito A, Bradley PJ, Rinaldo A, Scully C. Neck disease and distant metastases. Oral Oncol. 2003;39:207-12.

5. Jr DAR, Barboza CA, Clebis NK, de Moura SA, Lopes CAL. Prognostic significance of the anatomical location and TNM clinical classification in oral squamous cell carcinoma. Med Oral Patol Oral. 2008;13:E344-7.

6. Huber MA, Tantiwongkosi B. Oral and oropharyngeal cancer. Med Clin N Am. 2014;98:1299-321.

7. Dietl B, Marienhagen J, Schaefer C, Pohl F, Murthum T, Kölbl O. Survival with distant metastatic disease in head and neck cancer. A retrospective analysis. HNO. 2007;55:785-91.

8. Omar EA. The outline of prognosis and new advances in diagnosis of oral squamous cell carcinoma (OSCC) review of the literature. Journal of. Oral Oncol. 2013;2013 https://doi.org/10.1155/2013/519312

9. Omar E. Future imaging alternatives. The clinical non-invasive modalities in diagnosis of oral squamous cell carcinoma (OSCC). Open dentistry. Journal. 2015;9:311-8.

10. Sathiyasekar AC, Chandrasekar P, Pakash A, Kumar KU, Jaishlal MS. Overview of immunology of oral squamous cell carcinoma. Journal of Pharmacy \& Bioallied Sciences. 2016;8:S8-S12.

11. Nagler R. Saliva protein biomarkers to detect oral squamous cell carcinoma (OSCC). Oral Dis. 2016; https://doi.org/ 10.1111/odi.12617.

12. Scully C, Bagan JV. Recent advances in oral oncology 2008; squamous cell carcinoma imaging, treatment, prognostication and treatment outcomes. Oral Oncol. 2009;45:25-30.

13. Tamamaki N, Fujimori K, Nojyo Y, Kaneko T, Takauji R. Evidence that Sema3A and Sema3F regulate the migration of GABAergic neurons in the developing neocortex. J Comp Neurol. 2003;455:238-48.

14. Xiang RH, Hensel $\mathrm{CH}$, Garcia DK, Carlson HC, Kok K, Daly MC, et al. Isolation of the human semaphorin III/F gene (SEMA3F) at chromosome 3p21, a region deleted in lung cancer. Genomics. 1996;32:39-48.

15. Roche J, Boldog F, Robinson M, Robinson L, Varella-Garcia M, Swanton M, et al. Distinct 3p21.3 deletions in lung cancer and identification of a new human semaphorin. Oncogene. 1996;12:1289-97.

16. Sekido $Y$, Bader $S$, Latif F, Chen JY, Duh FM, Wei MH, et al. Human semaphorins $A(M)$ and IV reside in the 3p21.3 small cell lung cancer deletion region and demonstrate distinct expression patterns. Proc Natl Acad Sci USA. 1996; 93:4120-5.

17. Kusy S, Nasarre P, Chan D, Potiron V, Meyronet D, Gemmill RM, et al. Selective suppression of in vivo Tumorigenicity by Semaphorin SEMA3F in lung cancer cells. Neoplasia. 2005;7:457-65.

18. Xiang R, Davalos AR, Hensel CH, Zhou XJ, Tse C, Naylor SL. Semaphorin 3F gene from human 3p21.3 suppresses tumor formation in nude mice. Cancer Res. 2002;62:2637-43. 
19. Kessler O, Shraga-Heled N, Lange T, Gutmann-Raviv N, Sabo E, Baruch L, et al. Semaphorin-3F is an inhibitor of tumor angiogenesis. Cancer Res. 2004;64:1008-15.

20. Beuten J, Garcia D, Brand TC, He X, Balic I, Canby-Hagino E, et al. Semaphorin 3B and 3F single nucleotide polymorphisms are associated with prostate cancer risk and poor prognosis. J Urology. 2009;182:1614-20.

21. Zhou ZH, Rao J, Yang J, Wu F, Tan J, SL X, et al. SEMA3F prevents metastasis of colorectal cancer by PI3K-AKTdependent down-regulation of the ASCL2-CXCR4 axis. J Pathol. 2015;236:467-78.

22. Rao J, Zhou ZH, Yang J, Shi Y, SL X, Wang B, et al. Semaphorin-3F suppresses the stemness of colorectal cancer cells by inactivating Rac1. Cancer Lett. 2015;358:76-84.

23. Doçi CL, Mikelis CM, Lionakis MS, Molinolo AA, Gutkind JS. Genetic identification of SEMA3F as an Antilymphangiogenic metastasis suppressor gene in head and neck squamous carcinoma. Cancer Res. 2015;75:2937-48.

24. Yang G, Qu X, Zhang J, Zhao W, Wang H. Sema3F downregulates p53 expression leading to axonal growth cone collapse in primary hippocampal neurons. Int J Clin Exp Pathol. 2012:5:634-41.

25. Bielenberg DR, Hida Y, Shimizu A, Kaipainen A, Kreuter M, Kim CC, et al. Semaphorin 3F, a chemorepulsant for endothelial cells, induces a poorly vascularized, encapsulated, nonmetastatic tumor phenotype. J Clin Investig. 2004;114:1260-71.

26. Zhang B, Gao Z, Sun M, Li H, Fan H, Chen D, et al. Prognostic significance of VEGF-C, semaphorin 3F, and neuropilin-2 expression in oral squamous cell carcinomas and their relationship with lymphangiogenesis. J Surg Oncol. 2015;111:382-8.

27. Gao X, Tang C, Shi W, Feng S, Qin W, Tian J, et al. Semaphorin-3F functions as a tumor suppressor in colorectal cancer due to regulation by DNA methylation. Int J Clin Exp Pathol. 2015;8:12766-74.

28. Sun Y, Liegl R, Gong Y, Bühler A, Cakir B, Meng SS, et al. Sema3f protects against subretinal neovascularization in vivo. Ebiomedicine. 2017;18:281-7.

29. Liu MH, Fu WJ, Cui YH, Guo QN, Zhou Y. Downregulation of Semaphorin-3F is associated with poor prognostic significance in osteosarcoma patients. Am J Cancer Res. 2016;6:2252-62.

30. Nasarre P, Kusy S, Constantin B, Valérie CY, Harry ADZ, Bagnard D. Semaphorin SEMA3F has a repulsing activity on breast cancer cells and inhibits E-cadherin-mediated cell adhesion. Neoplasia. 2005;7:180-9.

31. Shimizu A, Mammoto A, Jr JEl, Pravda E, Dudley AC, Ingber DE, et al. ABL2/ARG tyrosine kinase mediates SEMA3Finduced RhoA inactivation and cytoskeleton collapse in human glioma cells. J Biol Chem2008;283: 27230-27238.

32. Xiong G, Wang C, Evers BM, Zhou BP, RORa XR. Suppresses breast tumor invasion through inducing SEMA3F expression. Cancer Res. 2012;72:1728-39.

\section{Submit your next manuscript to BioMed Central and we will help you at every step:}

- We accept pre-submission inquiries

- Our selector tool helps you to find the most relevant journal

- We provide round the clock customer support

- Convenient online submission

- Thorough peer review

- Inclusion in PubMed and all major indexing services

- Maximum visibility for your research

Submit your manuscript at www.biomedcentral.com/submit 